\title{
Uranium reduction in response to an influx of nitrate into organic-rich sediments
}

\author{
JEFFREY P. WESTROP ${ }^{1}$ POOJA YADAV ${ }^{1}$ VINCENT NOEL $^{2}$ \\ ARJEN VAN VEELEN ${ }^{2}$ JOHN R. BARGAR $^{2}$ ROMY \\ CHAKRABORTY ${ }^{3}$ KARRIE A. WEBER ${ }^{1,4}$ \\ ${ }^{1}$ University of Nebraska-Lincoln, Lincoln NE \\ (jwestrop@huskers.unl.edu; pyadav@huskers.unl.edu \\ kweber@unl.edu) \\ ${ }^{2}$ Stanford Linear Accelerator Center, Menlo Park, \\ CA(bargar@slac.stanford.edu; noel@slac.stanford.edu; \\ vveelen@slac.stanford.edu) \\ ${ }^{3}$ Lawrence Berkley National Laboratory, Berkley CA \\ (rchakraborty@lbl.gov) \\ ${ }^{4}$ Daugherty Water for Food Institute, Lincoln, NE
}

Uranium (U) mobility is strongly controlled by the redox state where U(IV) is generally poorly soluble and $\mathrm{U}(\mathrm{VI})$ is soluble and mobile. Redox changes can be stimulated by the influx of an oxidant, such as nitrate. Thus, the influx of oxidant into reduced sediments should result in net oxidation. Yet our prior research revealed that an influx of an oxidant can result in $\mathrm{U}$ immobilization rather than mobilisation as U(VI). Here we experimentally test the impact of nitrate influx on uranium mobility in batch reactors containing reduced, organic-rich, uranium contaminated oxbow lake sediments collected near Riverton WY amended with an anoxic bicarbonate buffered medium with and without a nitrate spike. Following the addition of the nitrate, aqueous U concentrations decreased (KPA and ICPMS). No significant decrease was observed in unamended controls. XANES analysis of sediments collected from treatments and controls revealed an increase in the amount of U(IV) relative to the unamended controls (85\% and $40 \%$ U(IV) respectively). This indicates that an influx of nitrate into the organic-rich sediments stimulated $U$ reduction. Supporting reducing conditions was the concurrent increase in aqueous $\mathrm{Fe}(\mathrm{II})$ indicative of $\mathrm{Fe}(\mathrm{III})$ reduction. While a decrease in sulphide was observed, PHREEQC modelling of geochemical data indicated Fe-sulphide precipitation. All geochemical changes were observed along with an increase in cell abundance. Together these results indicate that an influx of an low concentration of an oxidant, such as nitrate, a common anthropogenic contaminant, can stimulate reducing conditions and challenges our current understanding of $U$ mobility in natural systems. 